\title{
Hypothalamo-Pituitary-Adrenal Gland Axis in Mice Inhaling Toluene Prior to Low- Level Long-Term Exposure to Formaldehyde
}

\author{
Dwi Kesuma SARI ${ }^{1)}$, Sachi KUWAHARA ${ }^{1)}$, Masaru FURUYA ${ }^{1)}$, Yasuhiro TSUKAMOTO ${ }^{1)}$, Hajime HORI ${ }^{2)}$, \\ Naoki KUNUGITA ${ }^{2)}$, Keiichi ARASHIDANI ${ }^{2)}$, Hidekazu FUJIMAKI ${ }^{3)}$ and Fumihiko SASAKI ${ }^{1}$ * \\ ${ }^{1)}$ Laboratory of Veterinary Anatomy, Graduate School of Agriculture and Biological Sciences, Osaka Prefecture University, 1-1 Gakuen- \\ cho, Sakai, Osaka 599-8531, ')University of Occupational and Environmental Health, 1-1 Iseigaoka, Yahata-nishi-ku, Kitakyushu, \\ Fukuoka 807-8555 and ${ }^{3}$ National Institute for Environmental Studies, 16-2 Ibigawa, Tsukuba-shi, Ibaraki 305-8506, Japan
}

(Received 18 August 2004/Accepted 30 November 2004)

\begin{abstract}
We studied the change in the hypothalamo-pituitary-adrenal gland (HPA) axis upon adding prior toluene inhalation to our previous formaldehyde inhalation experiments to determine whether short term exposure to relatively high levels of toluene triggers multiple chemical sensitivity (MCS). Data come from immunocytochemical, morphometrical and RT-PCR measurements. Four groups of adult female mice were exposed to differing concentrations $(0,80,400$, and 2,000 ppb) of formaldehyde for $16 \mathrm{hr} /$ day, 5 days/week for twelve weeks, after the mice were exposed intranasally to $500 \mathrm{ppm}$ toluene per mouse for $6 \mathrm{hr} /$ day, for 3 days. We found that the number of corticotropin releasing hormone $(\mathrm{CRH})$-immunoreactive (ir) neurons was up-regulated according to the amount of formaldehyde as well as inhalation of formaldehyde alone in our previous experiment. The proportion of adrenocorticotropin hormone (ACTH)-ir cells increased according to the formaldehyde concentration, though there was no significant difference between the 400 and 2,000 groups. The number of ACTH-ir cells was higher in the 400 group than in the other groups $(0,80$, and 2,000). Expression of ACTH-mRNA was also up-regulated according to the quantity of formaldehyde. The sinusoid in the anterior pituitary showed more dilatation in the 400 and 2,000 groups than in the control group, especially in the 2,000 group. We propose that exposure to toluene prior to inhalation of formaldehyde has no effect on the HPA axis and as a trigger of MCS, although greater sinusoid dilatation was found in the anterior pituitary gland at higher concentrations of formaldehyde.

KEY WORDS: formaldehyde, hypothalamo-pituitary-adrenal gland axis, multiple chemical sensitivity, sinusoid, toluene.
\end{abstract}

J. Vet. Med. Sci. 67(3): 303-309, 2005

Multiple chemical sensitivity (MCS) in humans is a controversial disorder characterized by multi-organ symptoms in response to low-level exposure of chemicals that is considered safe for the general population [21-23]. MCS may develop in two stages: (1) loss of specific tolerance following acute or chronic exposure to various environmental agents, such as pesticide, solvents or contaminated air in a sick building, and (2) subsequent triggering of symptoms by extremely small quantities of chemicals, drugs and foods [13]. Sick building syndrome or sick house syndrome, which is a form of MCS, is characterized by non-specific complaints, including upper-respiratory irritative symptoms, headaches, fatigue and rashes. It is found in long term inhabitants of buildings who are exposed to low levels of formaldehyde $[9,10,20]$.

The hypothalamo-pituitary-adrenal gland (HPA) axis responds to stress, including chemical exposure [4, 12, 19, 28]. Our previous study [16] showed that long term lowlevel formaldehyde exposure may act on the HPA axis as a stressor. Ovalbumin (OVA) sensitization prior to formaldehyde inhalation may act synergically on the HPA axis with formaldehyde and may therefore trigger MCS [16].

Toluene is widely used in industry in glues, lacquers and paint removers $[5,26,27]$ and induces MCS in humans as well as formaldehyde [11].

\footnotetext{
* Correspondence to: Dr. Sasaki, F., Laboratory of Veterinary Anatomy, Osaka Prefecture University, 1-1 Gakuen- cho, Sakai, Osaka 599-8531, Japan.
}

Here, we aimed to observe the change in the HPA axis upon adding toluene inhalation to our previous formaldehyde inhalation study [16]. Specifically, we studied how toluene exposure prior to formaldehyde inhalation affects the HPA axis of mice and is particularly relevant in triggering MCS, by the use of immunocytochemical, morphometrical and RT-PCR methods.

\section{MATERIALS AND METHODS}

Animals and exposure: Female $\mathrm{C} 3 \mathrm{H} / \mathrm{He}$ mice were obtained from Charles River, Japan Inc. (Fukuoka, Japan) at 8 weeks of age and used in this experiment at 10 weeks. Food and water were given ad libitum. Formaldehyde was diluted with clean, filtered air to the desired concentration and introduced into $400 \mathrm{~L}$ stainless steel and glass chambers as described by Hori and Arashidani [7]. The concentration of formaldehyde in the chambers was measured chemically and continuously monitored by a formtector (XP-308; New Cosmos Electric Co., Japan).

Forty mice were divided into four groups of 10 each. These were designated as the 0 (control), 80, 400 and 2,000 groups, since they were respectively exposed to formaldehyde at concentrations of $0 \mathrm{ppb}$ (air), $82 \pm 6$ (Mean \pm SD) ppb, $393 \pm 34 \mathrm{ppb}$, and $1874 \pm 240 \mathrm{ppb}$ for $16 \mathrm{hr}$ (from 18:00 to 10:00) per day, 5 days per week, for 12 weeks according to the protocol of our previous study [16]. The mice were exposed intranasally to $500 \mathrm{ppm}$ toluene per 
mouse for $6 \mathrm{hr}$ per day, for 3 days prior to formaldehyde inhalation. The body weight of all mice was measured weekly. This experiment was approved by the University of Occupational and Environmental Health (Yahatanishi, Kitakyushu, Japan).

Immediately after their removal from the exposure facility, the 10 animals in each group were weighed and anesthetized by ip injection with Nembutal sodium at 09:00-11:00 $\mathrm{hr}$. The hypothalamus, half $(n=5)$ the samples of the pituitary gland and the adrenal gland were fixed, dehydrated and embedded in Tissue Prep as described previously [16]. The other five pituitaries per each group were mixed and analyzed together by RT-PCR methods as described previously [16]. The adrenal glands were cut in serial sections at $5 \mu \mathrm{m}$, and the sections were stained with hematoxylin-eosin and observed under an optical microscope.

Immunohistochemistry: All hypothalami were cut coronally in serial sections at $10 \mu \mathrm{m}$. Pituitaries were sagittally and serially cut at $5 \mu \mathrm{m}$. These sections were mounted on poly-L lysine $(50 \mu \mathrm{g} / \mathrm{m} l)$ coated slides. All immunocytochemical procedures for corticotropin releasing hormone $(\mathrm{CRH})$ neurons in the paraventricular nucleus (PVN) in the hypothalamus and adrenocorticotropic hormone (ACTH) cells in the anterior pituitary were processed as described previously [16].

Proliferating cell nuclear antigen (PCNA) and in situ apoptosis: PCNA and in situ apoptosis tests were performed to observe proliferation of neurons and nuclear DNA fragmentation in the PVN as described previously [16].

Morphometry: The number of $\mathrm{CRH}$-ir neurons was counted systematically at intervals of every fourth section of the PVN as described previously [16]. The number of sections for $\mathrm{CRH}$-ir neurons, selected from each animal, was $10.8 \pm 0.8$ (mean $\pm \mathrm{SE}$ ) for the 0 group, $10.6 \pm 0.5$ for the 80 group, $12.4 \pm 0.4$ for the 400 group and $11.6 \pm 0.5$ for the 2,000 group. The total number of the CRH-ir neuron (TC) was calculated using the formula: $\mathrm{n} / \mathrm{i} \times \sum \mathrm{N}_{\mathrm{i}}[15]\left(\sum \mathrm{N}_{\mathrm{i}}\right.$ : the number of $\mathrm{CRH}$-ir neurons in the number of sections (i) selected from the number of total sections (n) in the PVN of each mouse).

The areas $\left(A_{1}, A_{2}, \ldots, A_{n}\right)$ of the anterior pituitary of every tenth section were measured with an image analyzer (Cosmozone, 1SB, Nikon, Tokyo, Japan). The volume of the anterior pituitary $(\mathrm{V})$ was calculated as $\mathrm{V}=5 \times 10 \times \sum \mathrm{A}_{\mathrm{i}}$ $\mu \mathrm{m}^{3}$. The percentage and number of ACTH-ir cells were determined using a square of side $40 \mu \mathrm{m}$ drawn at $\times 400$ magnification on the screen of a personal computer [17]. About 2,000 adenohypophysial cell nuclei were counted in the lateral, parasagittal and midsagittal parts of the anterior pituitary of each animal. The numbers of ACTH-ir cells were expressed as percentages of at least 2,000 nuclei.

The total number (TA) of parenchymal cells in an anterior pituitary gland was calculated using the formula: $\bar{N}^{3 / 2} \times$ $/ 40^{3}[17](\hat{N}$ : the mean number of parenchymal cells per the square $\left(40^{2} \mu \mathrm{m}^{2}\right)$ with an image analyzer; $\mathrm{V}$ : the volume of anterior pituitary gland). The numbers of ACTH-ir cells were then calculated by multiplying TA by the proportion of ACTH-ir cells.

The areas $\left(\mathrm{AS}_{1}, \mathrm{AS}_{2}, \ldots, \mathrm{AS}_{\mathrm{n}}\right)$ of the sinusoid in the anterior pituitary gland were measured using the square $\left(40^{2}\right.$ $\mu \mathrm{m}^{2}$ ) with an image analyzer; about 20 areas (n) were measured at random in the lateral, parasagittal and midsagittal parts of the anterior pituitary of each animal. The percentage (PS) of the sinusoid in the anterior pituitary gland was calculated as $\mathrm{PS}=\left[\left(\mathrm{AS}_{1}+\mathrm{AS}_{2}+\ldots+\mathrm{AS}_{\mathrm{n}}\right) / \mathrm{n} \times 40^{2}\right] \times 100 \%$.

Statistical analysis: The body weight, adrenal weight, number of $\mathrm{CRH}$-ir neurons, the percentage and number of ACTH-ir cells, and the percentage of sinusoid in the anterior pituitary gland were all analyzed by one-way ANOVA followed by Fisher's least significant difference test with significant differences, which were assigned at the $5 \%$ probability level.

\section{RESULTS}

Body weight, weight of adrenal gland and volume of pituitary gland: The relative weight (adrenal weight/body weight) of the 80 group was significantly lower than that of controls $(F=4.82 ; \mathrm{p}<0.05)$ (Table 1$)$. No differences were found in body weight or in the volume of the pituitary gland between the control group and any other group (Table 1).

CRH-ir neurons in the PVN: The number of CRH-ir neurons was up-regulated according to the dose of formaldehyde inhaled (Figs. 1 and 2). CRH-ir neurons showed a significant increase in number in the 80 group, the 400 group and the 2,000 group, compared to the 0 group (control mice) $(F=48 ; \mathrm{p}<0.05)$.

$P C N A$ and apoptosis observation in the PVN: Proliferation and DNA fragmentation neurons were not found in the PVN at any group.

Table 1. Body weight, absolute and relative weight (adrenal weight/body weight) of the adrenal gland, and volume of the pituitary gland of mice exposed to toluene prior to inhalation of formaldehyde over 3 months

\begin{tabular}{lcccc}
\hline Groups & BW $(\mathrm{g})$ & $\mathrm{AW}(\mathrm{mg})$ & $\mathrm{AW} / \mathrm{BW}\left(\times 10^{-4}\right)$ & $\mathrm{VPG}\left(\times 10 \mu \mathrm{m}^{7}\right)$ \\
\hline 0 & $27.8 \pm 0.6$ & $6.5 \pm 0.2$ & $2.4 \pm 0.1$ & $92.8 \pm 8.3$ \\
80 & $28.4 \pm 0.5$ & $5.5 \pm 0.2^{*}$ & $1.9 \pm 0.1^{*}$ & $79.2 \pm 5.8$ \\
400 & $27.7 \pm 0.3$ & $6.3 \pm 0.3$ & $2.3 \pm 0.1$ & $90.4 \pm 2.5$ \\
2000 & $27.1 \pm 0.5^{\#}$ & $5.7 \pm 0.2^{*}$ & $2.1 \pm 0.1$ & $78.8 \pm 3.7$ \\
\hline
\end{tabular}

The values are expressed as mean \pm SE. $* p<0.05$ vs. control ( 0 group) and ${ }^{*} p<0.05$ vs. 80 group. BW: body weight, AW: adrenal weight, VPG: volume of anterior pituitary gland. The number of mice in each group is 10 except for VPG $(n=5)$. 


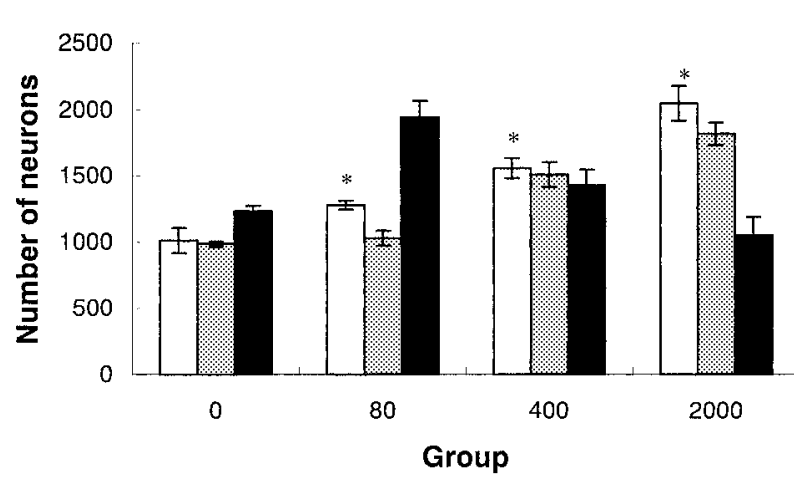

Fig. 1. Number of CRH-ir neurons in the PVN of mice exposed to toluene prior to inhalation of formaldehyde (empty bar), non allergy mice (gray bar) and allergy mice (filled bar) (data of non allergy and allergy mice were quoted from Ref. [16] as well as those of Figs. 3 and 4). Mice in 3 groups are designed as 0 (control), 80, 400 and 2,000 group mice, since they were exposed to formaldehyde at concentration of 0 (air), 80, 400 and 2,000 ppb over 3 months. Moreover, allergy mice injected intraperitoneally with $10 \mu \mathrm{g}$ ovalbumin (OVA) plus $2 \mathrm{mg}$ alum before formaldehyde inhalation. Non allergy and allergy mice were not exposed to toluene prior to inhalation of formaldehyde. Values are mean $\pm \mathrm{SE}(\mathrm{n}=5) .{ }^{*} \mathrm{p}<0.05$ vs. the 0 group (control).

ACTH-ir cells in the anterior pituitary gland: The percentage of ACTH-ir cells was up-regulated according to the quantity of formaldehyde inhaled, from $0 \mathrm{ppb}$ to $400 \mathrm{ppb}$ (Fig. 3). The percentage of ACTH-ir cells was higher $(F=82.51 ; \mathrm{p}<0.05)$ in the 80,400 and 2,000 groups than in the control group, though there was no significant difference between the 400 and 2,000 groups.

The number of ACTH-ir cells in the 400 group was significantly higher than in the control group $(F=8.35$; $\mathrm{p}<0.05)$ (Fig. 4).

The sinusoid in the anterior pituitary gland: There was considerable dilatation of the sinusoid in the anterior pituitary in the 400 and 2,000 groups relative to the control group (Figs. 5 and 6), especially in the 2,000 group. The percentage of sinusoid in the 2000 group was significantly greater than in the other groups $(F=165.1 ; \mathrm{p}<0.05)$.

Expression of ACTH-mRNA in the pituitary gland: It was also up-regulated according to the quantity of formaldehyde (Fig. 7).

Microscopic observation of the adrenal gland: No differences were found in the observations of the adrenal gland between any groups of mice, except for the weight of the adrenal gland as explained above.

\section{DISCUSSION}

The Ministry of Health and Welfare in Japan [14] proposed the guideline value (80 ppb) of the WHO [30] as an acceptable indoor concentration of formaldehyde. The WHO [31] found that average concentrations of formaldehyde are 40-280 ppb in homes or workplaces with environ- mental tobacco smoke, $800 \mathrm{ppb}$ in workplaces with occupational exposure, and 48,000-104,000 ppb in smokers (20 cigarettes/day). All the concentrations (80, 400 and $2,000 \mathrm{ppb}$ ) of formaldehyde used in our studies [16, present study] are within these values. We suggest that prolonged exposure to these concentrations of formaldehyde acts as a stressor on the HPA axis, because the number of CRH-ir neurons and ACTH-ir cells, and the expression of ACTH mRNA were up-regulated according to the dose of formaldehyde inhaled [16].

The WHO [31] found that the average indoor range of toluene concentrations is below $532 \mathrm{ppb}$ in the general population, $100 \mathrm{ppm}$ in the occupational inhalation group, and 0.2 $\mathrm{mg} /$ cigarette in cigarette smokers. Compared with these data, a $500 \mathrm{ppm}$ exposure of toluene in the present study is therefore a relatively high concentration in our environment.

The central nervous system (CNS) is the main target organ for the toxic action of volatile organic solvents such as toluene $[5,6]$. Toluene has neurotoxic effects [8]. Residual CNS damage is suspected after long term exposure to high concentrations of toluene [29]. Our previous study [16] showed that prolonged exposure to low-level formaldehyde increases the number of CRH-ir neurons in the PVN, acting as a stressor. In our results [16, present study], however, neither proliferating nor apoptotic neurons were found in PVN in any treatments such as formaldehyde, OVA and toluene. Thus, only CRH neurons that synthesized and secreted $\mathrm{CRH}$ in response to these stressor among all CRH neurons in the PVN may be immunohistocemically stained and become $\mathrm{CRH}$-ir neurons.

The number of CRH-ir neurons in the 0 (control) group of allergy mice was significantly higher than in the 0 (control) group of non allergy mice [16]. Therefore, OVA sensitization plays as a stressor to CRH neurons [16]. Furthermore, in the 80 group of allergy mice in the previous study [16], the number of CRH-ir neurons was significantly higher than in the 80 group of non allergy mice [16]. Thus, the OVA sensitization prior to inhalation of formaldehyde may give a larger stress than formaldehyde inhalation alone and act as a trigger of MCS [16]. However, the number of CRH-ir neurons was up-regulated according to the quantity of formaldehyde in the mice exposed to toluene prior to prolonged formaldehyde inhalation in the present study as well as non allergy mice in our previous study [16]. Thus, exposure to relative high level of toluene prior to prolonged formaldehyde inhalation did not have the same effect on the CRH neurons as OVA sensitization and did not act as a trigger of MCS.

The percentage of ACTH-ir cells as well as the serum level of ACTH, increases after exposure to cold stress over short times [18]. The data for ACTH-ir cells in the present study do differ significantly from the data of non allergy mice in our previous study of prolonged exposure to formaldehyde alone. In that study [16], the percentage and number of ACTH-ir cells of non allergy mice were up-regulated according to the quantity of formaldehyde. In the present study, the percentage of ACTH-ir cells increased likewise, 

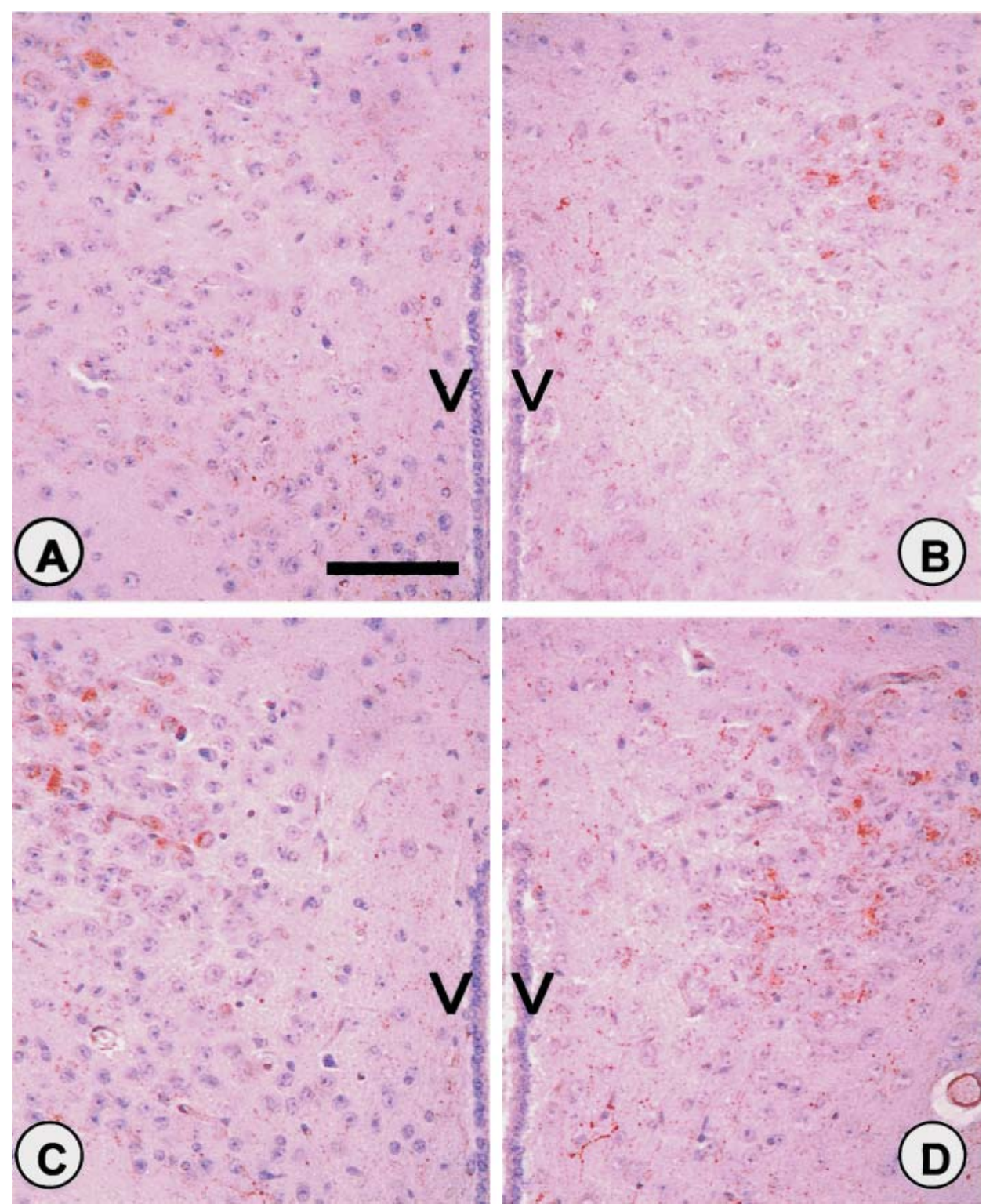

Fig. 2. CRH-ir neurons in the PVN of mice exposed to toluene prior to inhalation of formaldehyde over 3 months. (A) 0 group; (B) 80 group; (C) 400 group; (D) 2,000 group. The number of CRH-ir neurons was up-regulated according to the amount of formaldehyde inhaled. V: Third ventricle. Nuclei are stained with hematoxylin. Bar $=50 \mu \mathrm{m}$.

but there was no significant difference in the percentage between mice inhaling $400 \mathrm{ppb}$ and 2,000 ppb formaldehyde. Moreover, the number of ACTH-ir cells was significantly more numerous in mice inhaling $400 \mathrm{ppb}$ formaldehyde than in mice inhaling 0,80 and 2,000 ppb formaldehyde. The number of ACTH-ir cells was calculated according to factors such as the volume of the anterior pituitary, the number of nuclei of adenohypophyseal cells per fix area, and the percentage of ACTH-ir cells by the use of the formula proposed by Sasaki and Sano [17]. While the number of ACTH-ir cells is calculated using this formula, the area and number of all types of adenohypophyseal cells, sinusoids and other factors of the anterior pituitary could be also counted. In this study, there was no significant difference in the volume of the anterior pituitary between the 4 groups, but the number of adenohypophyseal cells per fix area was least in mice inhaling 2,000 ppb formaldehyde. As this main reason, we found that the sinusoid in the anterior pituitary shows much more dilatation in the 2,000 group than in the control group. In humans and mice, organic solvents produce physiological impairment of brain function following acute exposure $[2,25,32]$. Acute inhalation of 


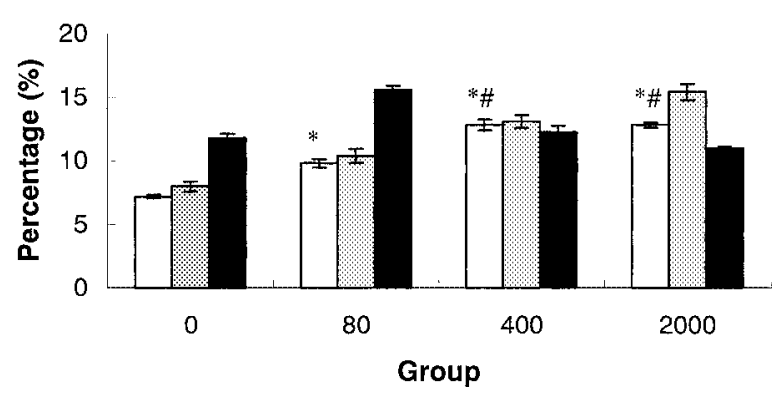

Fig. 3. Percentage of ACTH-ir cells in the anterior pituitary gland of mice exposed to toluene prior to inhalation of formaldehyde over 3 months (empty bar), non allergy mice (gray bar) and allergy mice (filled bar) (data of non allergy and allergy mice were quoted from Ref. [16]). Values are mean $\pm \mathrm{SE}$ $(\mathrm{n}=5) . * \mathrm{p}<0.05$ vs. the 0 group (control) and $\# \mathrm{p}<0.05$ vs. the 80 group.

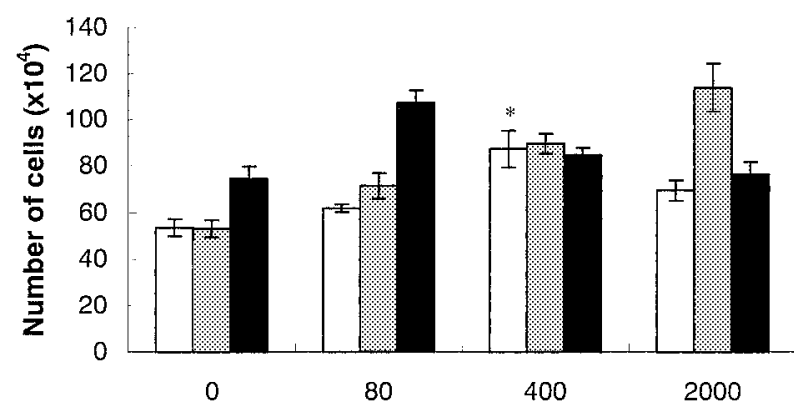

Fig. 4. Number of ACTH-ir cells in the anterior pituitary gland of mice exposed to toluene prior to inhalation of formaldehyde over 3 months (empty bar), non allergy mice (gray bar) and allergy mice (filled bar) (data of non allergy and allergy mice were quoted from Ref. [16]). Values are mean \pm SE ( $n=5)$. * $\mathrm{p}<0.05$ vs. the 0 group (control).

thinner, a kind of organic solvent, induces ultrastructural alteration of the liver, adrenal gland and CNS [3]: modifications in liver are a massive accumulation of glycogen, an increase of lipid droplets, the presence of numerous lysosomes and enlarged Golgi complex in the hepatocyte, and the deposition of the fibrous and collagen like materials between cells; some mitochondria in zona fasciculata of adrenal cortex became "megamitochondria" as described in literatures in alcoholism [1], cuprizone intoxication [24]; cerebral brain cortex shows an increase in the distance of intersynaptic space, a diminution of membrane density at postsynaptic membrane and modifications of size and shape of mitochondria in the neurons. We suspect that acute toluene inhalation and higher concentrations of formaldehyde might cause extensive dilatation of the sinusoid by acting directly on the anterior pituitary gland. However, inhalation in higher concentrations of formaldehyde alone did not cause any dilatation of the sinusoid in the anterior pituitary gland [16]. A further study would be needed to settle the question.
In conclusion, the results presented here suggest that toluene exposure prior to inhalation of formaldehyde has no effect on the HPA axis and as a trigger of MCS. However, extensive dilatation of the sinusoid was found in the anterior pituitary at higher concentrations of formaldehyde.

ACKNOWLEDGMENT. The authors thank Dr. A.F. Parlow (NIDDK), CA, U.S.A. for gifts of human ACTH antiserum. This study was supported in part by a grant from the Japanese Ministry of the Environment.

\section{REFERENCES}

1. Andrew, L.S. and Snyder, R. 1991. Toxic effects of solvent and vapors. pp. 681-722. In: Toxicology, The Basic Science of Poisons, 4th ed. (Amdur, M.O., Doull, J. and Klaassen, C.D. eds.), Pergamon Press, NY.

2. Antti-Poika, M., Ojala, M., Matikainen, E., Vaheri, E. and Juntunen, J. 1989. Occupational exposure to solvents and cerebellar, brainstem and vestibular functions. Int. Arch. Occup. Environ. Health 61: 397-401.

3. Carabez-T., A., Sandoval, F. and Palma, T. L. 1998. Ultrastructural changes of tissues produced by inhalation of thinner in rats. Microsc. Res. Tech. 40: 56-62.

4. Dallman, M.F., Akana, S.F., Laugero, K.D., Gomez, F., Manalo, S., Bell, M.E. and Bhatnagar, S. 2003. A spoonful of sugar: feedback signals of energy stores and corticosterone regulate responses to chronic stress. Physiol. Behav. 79: 3-12.

5. Filley, C.M., Halliday, W. and Kleinschmidt-DeMaster, B.K. 2004. The effect of toluene on the central nervous system. $J$. Neuropathol. Exp. Neurol. 63: 1-12.

6. Gralewicz, S. 1992. Organic solvents and time-dependent sensitization. Int. J. Occup. Med. Environ. Health 12: 371-381.

7. Hori, H. and Arashidani, K. 1997. Basic characteristics of a formaldehyde gas generator using solid paraformaldehyde. $J$. Univ. Occup. Env. Health 19: 123-131.

8. Hsieh, G.C., Sharma, R.P. and Parker, R.D. 1991. Hypothalamic-pituitary-adrenal axis activity and immune function after oral exposure of benzene and toluene. Immunopharmacology 21: 23-31.

9. Kilburn, K.H. 2000. Indoor air effects after building renovation and in manufactured homes. Am. J. Med. Sci. 320: 249-254.

10. Kim, W.J., Terada, N., Nomura, T., Takahashi, R., Lee, S.D., Park, J.H. and Konno, A. 2002. Effect of formaldehyde on the expression of adhesion molecules in nasal microvascular endothelial cells: the role of formaldehyde in the pathogenesis of sick building syndrome. Clin. Exp. Allergy 32: 287-295.

11. Lee, Y.L., Pai, M.C., Chen, J.H. and Guo, Y.L. 2003. Central neurological abnormalities and multiple chemical sensitivity caused by chronic toluene exposure. Occup. Med. (Lond.) 53: 479-482.

12. Makino, S., Hashimoto, K. and Gold, P.W. 2002. Multiple feedback mechanisms activating corticotropin-releasing hormone system in the brain during stress. Pharmacol. Biochem. Behav. 73: 147-158.

13. Miller, C.S. 1996. Chemical sensitivity: symptom, syndrome or mechanism for disease? Toxicology 111: 69-86.

14. Ministry of Health Welfare of Japan. 1997. The Proceedings of the Meeting on Comfortable and Healthful House, Japan (in Japanese).

15. Nurhidayat, Tsukamoto, Y., Sigit, K. and Sasaki, F. 1999. Sex differentiation of growth hormone-releasing hormone and 

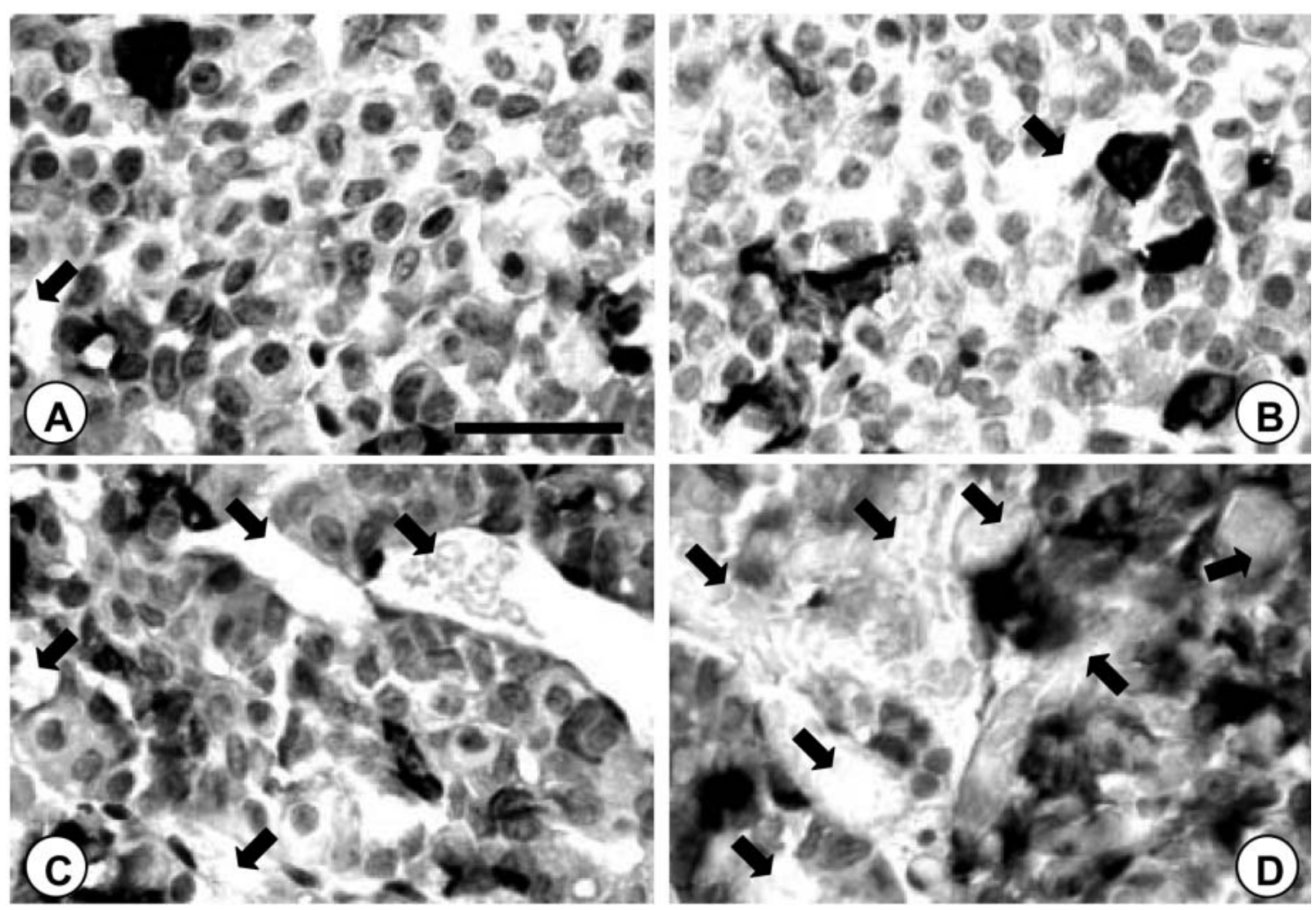

Fig. 5. ACTH-ir cells in the anterior pituitary gland of mice exposed to toluene prior to inhalation of formaldehyde over 3 months. (A) 0 group; (B) 80 group; (C) 400 group; (D) 2,000 group. The sinusoid is shown by the arrow. The sinusoid in the 400 and 2,000 groups shows more dilatation compared with that of the control. Nuclei are stained with hematoxylin. Bar $=30 \mu \mathrm{m}$.

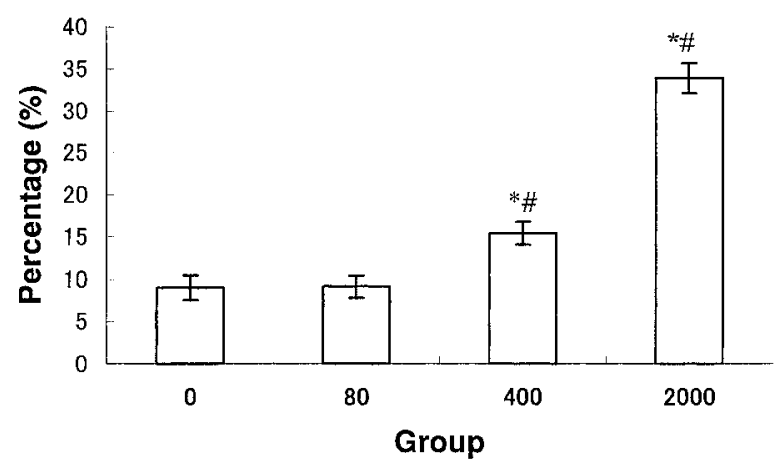

Fig. 6. Percentage of sinusoid area in the anterior pituitary gland of mice exposed to toluene prior to inhalation of formaldehyde over 3 months. The percentage is higher in the 400 and 2,000 groups than in the control group. Values are mean $\pm \mathrm{SE}(\mathrm{n}=5)$. ${ }^{*} \mathrm{p}<0.05$ vs. the 0 group (control) and ${ }^{\#} \mathrm{p}<0.05$ vs. the 80 group.

somatostatin neurons in the mouse hypothalamus: an immunohistochemical and morphological study. Brain Res. 821: 309321.

16. Sari, D.K., Kuwahara, S., Tsukamoto, Y., Hori, H., Kunugita, N., Arashidani, K., Fujimaki, H. and Sasaki, F. 2004. Effect of prolonged exposure to low concentrations of formaldehyde on the corticotropin releasing hormone neurons in the hypothalamus and adrenocorticotropic hormone cells in the pituitary gland in female mice. Brain Res. 1013: 107-116.

17. Sasaki, F. and Sano, M. 1982. Role of the ovary in the sexual differentiation of prolactin and growth hormone cells in the mouse adenohypophysis: a stereological morphometric study by electron microscopy. J. Endocrinol. 93: 117-121.

18. Sasaki, F., Wu, P., Rougeau, D., Unabia, G. and Childs, G.V. 1990. Cytochemical studies of responses of corticotropes and thyrotropes to cold and novel environment stress. Endocrinology 127: 285-297.

19. Seasholtz, A. 2000. Regulation of adrenocorticotropic hormone secretion: lessons from mice deficient in corticotropinreleasing hormone. J. Clin. Invest. 105: 1187-1188.

20. Skov, O. and Valbjorn, DISG. 1987. The sick building syndrome in the office environment: The Danish Town Hall study. Environ. Int. 13: 339-349.

21. Sorg, B.A. and Hochstatter, T. 1999. Behavioral sensitization after repeated formaldehyde exposure in rats. Toxicol. Ind. Health 15: 346-355.

22. Sorg, B.A., Bailie, T.M., Tschirgi, M.L., Li, N. and Wu, WRan. 2001. Exposure to repeated low-level formaldehyde in rats increased basal corticosterone levels and enhances the corticosterone response to subsequent formaldehyde. Brain Res. 898: $314-320$. 
A
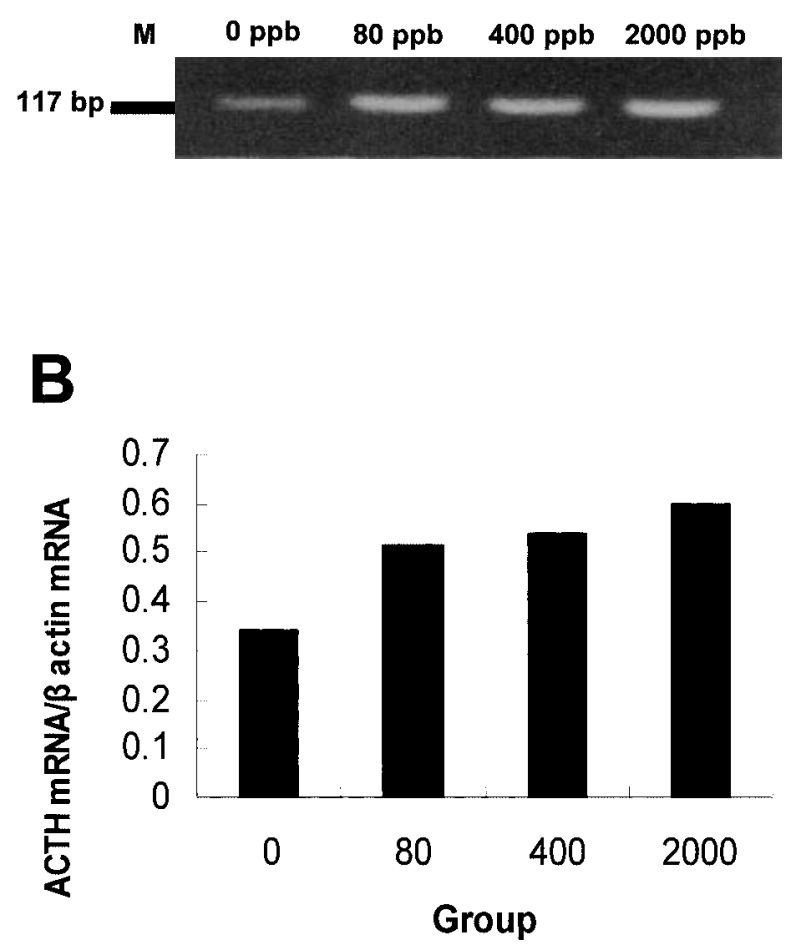

Fig. 7. Expression of ACTH-mRNA in the pituitary gland of mice exposed to toluene prior to inhalation of formaldehyde over 3 months using RT-PCR (A) and the intensity relative to that of $\beta$-actin mRNA (B). The size of the amplification bands of ACTH was $117 \mathrm{bp}$. Five pituitaries in each group were mixed and analyzed together.
23. Sorg, B.A., Willis, J.R., See, R.E., Hopkins, B. and Westberg, H.H. 1998. Repeated low-level formaldehyde exposure produces cross sensitization to cocaine: possible relevance to chemical sensitivity in humans. Neuropsychopharmacology 18: 385-394.

24. Susuki, K. 1969. Giant hepatic mitochondria production in mice fed with cuprizone. Science 163: 81-82.

25. Svensson, B.G., Nise, G., Englander, V., Attewell, R., Skerfving, S. and Moller, T. 1990. Deaths and tumours among rotogravure printers exposed to toluene. Br. J. Ind. Med. 47: $372-$ 379.

26. von Euler, G., Ogren, S.O., Bondy, S.C., McKee, M., Warner, M., Gustafsson, J.A., Eneroth, P. and Fuxe, K. 1991. Subacute exposure to low concentrations of toluene affects dopaminemediated locomotor activity in the rat. Toxicology 67: 333349.

27. von Euler, G., Ogren, S.O., Li, X.M., Fuxe, K. and Gustafsson, J.A. 1993. Persistent effects of subchronic toluene exposure on spatial learning and memory, dopamine-mediated locomotor activity and dopamine D2 agonist binding in the rat. Toxicology 77: 223-232.

28. Whitnall, M.H. 1993. Regulation of the hypothalamic corticotropin-releasing hormone neurosecretory system. Prog. Neurobiol. 40: 573-629.

29. The International Programme on Chemical Safety (IPCS). 1985. Environmental Health Criteria 52 Toluene. WHO Regional Publications. Geneva. WHO.

30. World Health Organization. 1987. WHO air guidelines for Europe. Copenhagen. WHO Regional Office for Europe. WHO Regional Publications. Europe Series No. 23. Geneva. WHO.

31. World Health Organization. 2000. WHO air guidelines for Europe. Copenhagen. WHO Regional Office for Europe. WHO Regional Publications. Europe Series. Geneva. WHO.

32. Yamada, K. 1993. Influence of lacquer thinner and some organic solvents on reproductive and accessory reproductive organs in the male rat. Biol. Pharm. Bull. 16: 425-427. 